University of Wollongong

Research Online

Faculty of Social Sciences - Papers (Archive) Faculty of Arts, Social Sciences \& Humanities

2016

Alprazolam use and related harm among opioid substitution treatment clients - 12 months follow up after regulatory rescheduling

Rachel M. Deacon

University of Sydney

Suzanne Nielsen

University of New South Wales

Stefanie Leung

University of Sydney

Gonzalo Rivas

South Eastern Sydney Local Health District

Tim Cubitt

St Vincent's Hospital

See next page for additional authors

Follow this and additional works at: https://ro.uow.edu.au/sspapers

Part of the Education Commons, and the Social and Behavioral Sciences Commons

Research Online is the open access institutional repository for the University of Wollongong. For further information contact the UOW Library: research-pubs@uow.edu.au 


\title{
Alprazolam use and related harm among opioid substitution treatment clients - 12 months follow up after regulatory rescheduling
}

\author{
Abstract \\ Background Alprazolam, has been associated with disproportionate harms compared to other \\ benzodiazepines, especially among people in opioid substitution treatment (OST). We examine the effect \\ of the rescheduling of alprazolam in Australia, from Schedule 4 to Schedule 8 in February 2014 amongst a \\ high-risk population of clients in OST. Methods OST participants who reported recent (last month) \\ alprazolam use were recruited from three Sydney clinics. Participants $(n=57)$ were interviewed \\ immediately prior to rescheduling and again three months and 12 months after rescheduling. We \\ examined self-reported patterns of drug use, drug availability, mental and physical health. A linear mixed \\ models approach was used to analyse changes in alprazolam and other benzodiazepine use. Results \\ Mean days of alprazolam use in the past 28 days decreased from 13.7 to 7.1 days, and mean weekly \\ alprazolam dose decreased from $15.1 \mathrm{mg}$ to $6.1 \mathrm{mg}$ at 12 months follow-up $(p=0.001)$. Total weekly \\ benzodiazepine use also reduced from a mean of $222 \mathrm{mg}$ diazepam equivalent to $157 \mathrm{mg}(p=0.044)$. \\ Other substance use did not change significantly. Reported mode of cost price of street alprazolam \\ doubled from $\$ 5$ to $\$ 10$ over the 12-month period. Conclusion Alprazolam rescheduling resulted in an \\ overall reduction in alprazolam and total benzodiazepine use, without substitution with other drugs, in the \\ short term. Unintended harms were not observed. Rescheduling appears to have been effective in \\ reducing alprazolam use in this high-risk population.
}

\section{Keywords}

substitution, treatment, clients, - , 12, months, follow, up, after, alprazolam, related, harm, regulatory, among, rescheduling, opioid

\section{Disciplines}

Education | Social and Behavioral Sciences

\section{Publication Details}

Deacon, R. M., Nielsen, S., Leung, S., Rivas, G., Cubitt, T., Monds, L. A., Ezard, N., Larance, B. \& Lintzeris, N. (2016). Alprazolam use and related harm among opioid substitution treatment clients - 12 months follow up after regulatory rescheduling. International Journal of Drug Policy, 36 104-111.

\section{Authors}

Rachel M. Deacon, Suzanne Nielsen, Stefanie Leung, Gonzalo Rivas, Tim Cubitt, Lauren A. Monds, Nadine Ezard, Briony K. Larance, and Nicholas Lintzeris 


\section{TITLE:}

\section{ALPRAZOLAM USE AND RELATED HARM AMONG OPIOID SUBSTITUTION TREATMENT CLIENTS - 12 MONTHS FOLLOW UP AFTER REGULATORY RESCHEDULING}

This article has been published:

Full citation: Deacon R, Nielsen S, Leung $\mathrm{S}$, et al. Alprazolam use and related harm among opioid substitution treatment clients - 12 months follow up after regulatory rescheduling. International Journal of Drug Policy 2016; In Press (Accepted 010616).

The final published version can be found here: doi: 10.1111/add.13517

Running title: 12 month outcomes of alprazolam rescheduling among OST clients

\section{Authors:}

Rachel M. Deacon ${ }^{1,2}$ (Rachel.deacon@sydney.edu.au), Suzanne Nielsen ${ }^{1,3}$ (suzanne.nielsen@unsw.edu.au), Stefanie Leung ${ }^{2}$ (stefanie.y.leung@uni.sydney.edu.au), Gonzalo Rivas ${ }^{1}$ (gonzalo.rivas@sesiahs.health.nsw.gov.au),Tim Cubitt (tim.cubitt@gmail.com), Lauren A. Monds ${ }^{1,2}$ (lauren.monds@sydney.edu.au), Nadine Ezard ${ }^{4,5}$ (nadine.ezard@svha.org.au), Briony Larance ${ }^{3}$ (b.larance@unsw.edu.au), Nicholas Lintzeris ${ }^{1,2}$ (nicholas.lintzeris@sesiahs.health.nsw.gov.au)

\section{Affiliations:}

${ }^{1}$ Drug and Alcohol Services, South Eastern Sydney Local Health District, 591 South Dowling St, Surry Hills 2010, Australia

${ }^{2}$ Central Clinical School, University of Sydney, Sydney, NSW, Australia

${ }^{3}$ National Drug and Alcohol Research Centre, UNSW Australia, Sydney, New South Wales 2052, Australia

${ }^{4}$ Alcohol and Drug Service, St Vincent's Hospital, Sydney, Australia.

${ }^{5}$ Faculty of Medicine, UNSW Australia, Sydney, Australia

\section{Corresponding Author:}

Rachel Deacon

Rachel.deacon@sydney.edu.au

The Langton Centre, 591 South Dowling St, Surry Hills NSW 2010.

Ph: 029332 8731, Fax: 93328700

Word count: 3997 (excluding references, tables, abstract)

Figure/table count: 4 tables, 1 figure 


\section{ALPRAZOLAM USE AND RELATED HARM AMONG OPIOID SUBSTITUTION TREATMENT \\ CLIENTS - 12 MONTHS FOLLOW UP AFTER REGULATORY RESCHEDULING}

\section{Background:}

Alprazolam, has been associated with disproportionate harms compared to other benzodiazepines, especially among people in opioid substitution treatment (OST). We examine the effect of the rescheduling of alprazolam in Australia, from Schedule 4 to Schedule 8 in February 2014 amongst a high-risk population of clients in OST.

\section{Methods:}

OST participants who reported recent (last month) alprazolam use were recruited from three Sydney clinics. Participants $(n=57)$ were interviewed immediately prior to rescheduling and again three months and 12 months after rescheduling. We examined self-reported patterns of drug use, drug availability, mental and physical health. A linear mixed models approach was used to analyse changes in alprazolam and other benzodiazepine use.

\section{Results:}

Mean days of alprazolam use in the past 28 days decreased from 13.7 to 7.1 days, and mean weekly alprazolam dose decreased from $15.1 \mathrm{mg}$ to $6.1 \mathrm{mg}$ at 12 months follow-up $(p=0.001)$. Total weekly benzodiazepine use also reduced from a mean of $222 \mathrm{mg}$ diazepam equivalent to $157 \mathrm{mg}(\mathrm{p}=0.044)$. Other substance use did not change significantly. Reported mode of cost price of street alprazolam doubled from $\$ 5$ to $\$ 10$ over the 12 month period.

\section{Conclusion:}

Alprazolam rescheduling resulted in an overall reduction in alprazolam and total benzodiazepine use, without substitution with other drugs, in the short term. Unintended harms were not observed. Rescheduling appears to have been effective in reducing alprazolam use in this high-risk population.

Keywords: alprazolam, opioid substitution treatment, prescription drug misuse, benzodiazepines 


\section{Background}

Benzodiazepine misuse among opioid-substitution treatment (OST) clients is both highly prevalent (Chen et al., 2011; Darke et al., 2010; Iguchi, Handelsman, Bickel, \& Griffiths, 1993; Lavie, Fatseas, Denis, \& Auriacombe, 2009; Nielsen, Dietze, Lee, Dunlop, \& Taylor, 2007; Peles, Schreiber, \& Adelson, 2010) and associated with a number of adverse outcomes (Ashton, 2005; Lintzeris \& Nielsen, 2010). These include reduced likelihood of opioid abstinence (Kamal et al., 2007), early withdrawal from treatment (Meiler, Mino, Chatton, \& Broers, 2005; Peles et al., 2010), increased use of other psychotropic drugs and greater levels of anxiety and depression (Lavie et al., 2009), participation in crime and injecting-related risks (Darke, Hall, Ross, \& Wodak, 1992). Benzodiazepine misuse among OST clients presents a serious public health risk as these individuals are at increased risk for multiple drug overdoses (Chen et al., 2011). Internationally, benzodiazepines are commonly implicated in opioid-related mortality (Park, Saitz, Ganoczy, Ilgen, \& Bohnert, 2015), with alprazolam the most commonly prescribed benzodiazepine in the US (IMS Institute for Healthcare Informatics, 2015) and most frequently implicated benzodiazepine in emergency department drug-related presentations (Substance Abuse and Mental Health Services Administration, 2013).

In the general population in Australia, benzodiazepine use has been gradually decreasing since 1992, with the exception of alprazolam where an 8-plus fold increase in alprazolam use was observed between 1992 and 2011 (Islam, Conigrave, Day, Nguyen, \& Haber, 2014). Whilst not all OST clients experience harms or dependence on benzodiazepines (Lintzeris \& Nielsen, 2010), approximately one third (38\%) of clients at two public OST services in Sydney self-report benzodiazepine use in the past 28 days (Deacon et al., 2014).

Alprazolam has been thought to be associated with a disproportionate amount of harm compared to other benzodiazepines (Horyniak, Reddel, Quinn, \& Dietze, 2012; Moylan, Giorlando, Nordfjaern, \& Berk, 2012; Moylan et al., 2011). Alprazolam is considered a high potency benzodiazepine compared to other benzodiazepines (Truven Health Analytics). Due to its short elimination half-life and high potency it has been identified to be particularly problematic with respect to dependence liability and withdrawal seizures (Wolf \& Griffiths, 1991). Among patients on methadone programs, alprazolam has been associated with aggression and problematic potentiation of both drugs (K. Jones, Nielsen, Bruno, Frei, \& Lubman, 2011). There have been increased alprazolam detections reported with heroin-related overdoses (Rintoul, Dobbin, Nielsen, Degenhardt, \& Drummer, 2013), an overrepresentation of alprazolam in overdose cases (Buykx, Loxley, Dietze, \& Ritter, 2010) and an increased risk of overdose with alprazolam in general (Isbister, O'Regan, 
Sibbritt, \& Whyte, 2004). Driving accidents and seizures are also associated with alprazolam use (Nielsen et al., 2008).

More stringent regulation is one public health approach in response to concerns about illicit or harmful use of medicines. A recent example is the rescheduling of hydrocodone, a commonly misused opioid analgesic in the US. Compared to the 36 months before rescheduling in October 2014, the number of hydrocodone prescriptions decreased by $22 \%$ and volume of dispensed hydrocodone product decreased by $16 \%$ in the following 12 months (C. M. Jones, Lurie, \& Throckmorton, 2016). A modest (4.9\%) increase in nonhydrocodone opioid analgesic prescriptions did not substantially offset the drop in hydrocodone. In response to concerns with alprazolam, increased restrictions around alprazolam supply were introduced in Australia on 1 February 2014, when this medication was re-categorised from Schedule 4 to Schedule 8. With this change came jurisdictional modifications in storage and prescribing requirements. For example, in NSW doctors must now obtain a specific authority from Pharmaceutical Services in the Ministry of Health to prescribe alprazolam for an extended period of time (> two months in New South Wales [NSW]) or prior to prescribing alprazolam to a drug dependent patient (this includes all OST patients as defined in the NSW Therapeutic Drugs \& Poisons Act ("Poisons and Therapeutic Goods Act 1966 [statute on the internet],")). Reduced availability is intended to reduce inappropriate use and harms. However, it is unclear as to whether such regulatory changes are effective in modifying access and use in those individuals at greatest risk of experiencing harms. Furthermore, restrictions in access to alprazolam could also be associated with unanticipated harms such as withdrawal syndromes in dependent individuals (presenting with seizures, panic attacks, anxiety, delirium) or increases in the use of other (and potentially more harmful) substances or routes of administration (e.g. injected opioids).

This study aimed to assess the intended and unintended consequences of rescheduling alprazolam, to examine the impact of regulatory policy changes in this high-risk population. Drug use and wellbeing were examined in alprazolam-using OST clients in the periods immediately before, three months and twelve months after the regulatory changes, using a prospective longitudinal cohort design. 


\section{Methods}

\section{Study design}

The study used a longitudinal cohort design to examine a range of outcomes in a group of alprazolam using OST clients immediately before, three months and 12 months after the rescheduling of alprazolam on $1^{\text {st }}$ February 2014. Participants were recruited from three public specialist OST clinics in Sydney: The Langton Centre, St George Drug and Alcohol Service (both services of Drug and Alcohol Services, South East Sydney Local Health District) and Rankin Court (Alcohol and Drug Service, St Vincent's Hospital), representing approximately 750 OST clients. Eligible participants were required to have been on OST (methadone or buprenorphine) at one of the study clinics for at least one month prior to being interviewed and to have self-reported use of alprazolam at least once in the past month. Exclusion criteria included severe mental health (e.g. acute psychosis, delirium) and/or severe cognitive deficits preventing informed consent, an impending custodial sentence or transfer to another service precluding participation in the followup interviews. Participants were required to attend three structured interviews (each approximately two hours in duration) with an independent researcher: one month before, three months and 12 months following the rescheduling. The study was advertised with fliers displayed in the clinics, as well as potentially eligible clients being referred by clinicians. Participants received a $\$ 40$ supermarket voucher for reimbursement of time and effort at the conclusion of each interview.

Ethical approval was provided by the South Eastern Sydney Local Health District Human Research Ethics Committee (HREC/13/POWH/465) with site approval by St Vincent's Hospital Sydney Human Research Ethics Committee. It conforms to the provisions of the Declaration of Helsinki (as revised in Tokyo 2004). 


\section{$\underline{\text { Measures }}$}

Baseline demographic data was collected for all participants. Both pre- and post-rescheduling interviews explored participants' drug use including a 28-day recall of days of alcohol, illicit and pharmaceutical drug use, a detailed 7-day history of drug use (including amount used, source (illicit or licit/prescription) and cost (illicit or licit)) using time-line follow-back techniques, lifetime history of benzodiazepine and other sedative use and current OST treatment type. Participants were also asked if they had experienced any non-fatal overdoses in the last three months as a result of their benzodiazepine use. Cognition was measured with the Montreal Cognitive Assessment (MOCA) (Nasreddine et al., 2005), designed to distinguish participants with mild cognitive impairment (MOCA score less than 26/30) from those with normal cognition. Mental and physical health was measured with the SF-36v2 Health Survey (Ware \& Sherbourne, 1992), a 36 item validated scale which measures general physical component scores (PCS) and mental health component scores (MCS). Normative scores based on US 1998 data are mean 50 and standard deviation 10. The short version (21 item) of the Depression Anxiety Stress Scales, or DASS, (Lovibond \& Lovibond, 1995) was used to measure depression, anxiety and stress. Cut-off scores out of 21 for severe or very severe depression, anxiety and/or stress are 11+, 8+ and 13+ respectively. The Insomnia Severity Index, or ISI, (Bastien, Vallieres, \& Morin, 2001) - a 7-item scale with a total score of 28 , where a score of 15 or above indicates clinically significant insomnia - was used to assess sleep.

Benzodiazepine use was reported as (i) mean dose (mg) used in the last seven days and (ii) mean days of use in the last 28. Standard deviation (SD) was reported for each measure. Where different benzodiazepine types were combined, quantities consumed were converted into oral diazepam equivalent doses using available references (National Prescribing Service, 1999; Therapeutic Guidelines Limited, 2013). The alprazolam equivalent dose used was $0.5 \mathrm{mg}$ to $5 \mathrm{mg}$ diazepam. 


\section{$\underline{\text { Analysis }}$}

Analysis was conducted in SPSS version 21. Descriptive statistics were used to describe baseline characteristics of the cohort - current OST treatment, gender, age, employment, homelessness, education, and mental and physical health. Parametric tests (e.g. means, t-test) were used for normally-distributed data, and non-parametric tests (e.g. medians, Wilcoxon signed rank test) for skewed data. The characteristics of participants who were and were not followed up at 12 months were compared.

Linear mixed models were used to model changes in alprazolam and all benzodiazepine use over the three waves of data collection. A mixed model approach was selected to account for correlation between repeated measures, allow for both fixed and random effects, and impute missing data. The outcome variables for the four models were: (i) mean total mgs used in the last seven days and (ii) mean days of use in the last 28 for alprazolam; and (iii) total diazepam equivalent mgs used in the last seven days and (iv) mean days of use for all benzodiazepines. For each model, an autoregressive covariance structure was chosen with interview wave as the repeated measure and participants as the subject grouping. The intercept was included as a random effect and maximum likelihood estimation was used. Base models were calculated using only interview wave as a fixed predictive variable. Then other participant characteristics variables expected to influence benzodiazepine use were included in the model based on forward selection, with Akaike's Information Criterion (AIC) used to judge improved model fit. These were recruitment site, age, gender, cognition (MOCA score), physical health (PCS), depression, anxiety, and stress (using individual DASS subscale scores), and insomnia (ISI score). Base and best-fit model estimations at each interview wave are reported for each outcome variable.

Complete case analysis using descriptive statistics was used to explore the use of non-benzodiazepine drug classes including heroin, pharmaceutical opioids, amphetamines, cocaine, cannabis, alcohol, antidepressants and antipsychotics, as well as overdose reports, over the three waves of data. Data from those participants who were not interviewed at follow up one and two were not used for this sub-analysis as descriptive statistics cannot account for missing data. 


\section{Results}

\section{Baseline demographics}

A flow diagram illustrating the number of participants at each wave is shown in Figure one. From an estimated pool of 750 OST clients across 3 clinics of which an estimated 285 or 38\% (Deacon et al., 2014) would have used benzodiazepines (not necessarily alprazolam) in the last month, the total number of participants recruited was 57 . Sixty one participants were screened for eligibility, with three of them not meeting eligibility criteria (no reported alprazolam use in the last 28 days). Of the 58 eligible participants, 57 completed the baseline interview, $48(84 \%)$ completed the three month interview and $35(61 \%)$ completed the 12-month interview. Of the 22 participants lost to follow-up, 10 remained clients of the OST clinic but either declined further interview $(n=8)$ or were too unwell $(n=2)$. Demographic, mental and physical health measures at baseline comparing the 35 participants followed up with the 22 participants lost to follow-up are presented in Table one.

\section{$<$ Insert Figure one here $>$ $<$ Insert Table one here $>$}

At baseline, $60 \%$ percent of participants were male and their mean age was 44 years. Thirty three percent had completed high school education, seven percent were currently employed and nine percent were homeless. Most (82\%) were prescribed oral methadone, the remainder sublingual buprenorphine/naloxone. Participants reported a median of 15 years of regular benzodiazepine use (defined as the number of years since >one month without using benzodiazepines), ranging from one to 53 years. Twenty eight percent met the cut-off for normal cognitive functioning (MoCA >26/30). The only significant differences in baseline characteristics between participants followed up and not followed up at 12 months (Table one), was years of regular benzodiazepine use ( 24.5 years use compared to 8.5 for those followed up, $p=0.002$ ).

\section{Changes in alprazolam and other benzodiazepine use}

After alprazolam, the most frequently used benzodiazepines were, in order, diazepam, clonazepam, oxazepam, temazepam, nitrazepam and flunitrazepam. One person reported using zolpidem, a Z-hypnotic, at follow-up. As the effects of zolpidem are broadly similar to benzodiazepines, it was combined with benzodiazepines. Proportions of participants using diazepam (68\%), clonazepam (37\%), other benzodiazepines (19\%), and any non-alprazolam benzodiazepines (77\%) in the previous 28 days at baseline 
did not change significantly at follow-up. However, alprazolam use did drop from $100 \%$ use at baseline to $36 / 28(75 \%)$ use at three months and 20/45 (67\%) use at 12 months follow-up.

\section{<Insert table two here>}

Table two presents the four linear mixed models for changes in volume and frequency of alprazolam and all benzodiazepine use over the three waves of data collection. The base model for Model one (total seven day alprazolam load) showed a significant $(p=0.007)$ decrease at three months which was maintained $(p=0.001)$ at 12 months post-rescheduling. After controlling for the covariates that improved model fit (PCS, depression, stress, ISI), time still remained a significant predictor of use. Alprazolam load decreased from a mean of $15.1 \mathrm{mg}$ at baseline to $6.1 \mathrm{mg}$ at 12 months follow-up ( $p=0.001)$. Similarly, days of alprazolam use in the previous 28 (Model two, Table two) significantly decreased at both three and 12 months, and nearly halved from 13.7 days at baseline to 7.1 days at 12 months follow-up (best-fit model controlled for physical component score, insomnia and anxiety; $p=0.001$ ).

There was no significant change in the seven day load of all benzodiazepines (diazepam equivalent) at three months (Model three: best-fit controlled for physical component score, insomnia and anxiety; $p=0.972$ ). However, at 12 months follow-up load had dropped from $225 \mathrm{mg}$ to $151 \mathrm{mg}(p=0.028)$. Days of use in the past 28 of all benzodiazepines did not reach significance after controlling for physical component score and insomnia (Model four; $p=0.065$ ).

A sensitivity analysis was carried out (results not presented) to assess the effect of the major nonbenzodiazepine drug use classes (cannabis, alcohol, methamphetamine and heroin) on the four linear mixed models, but no significant effects on benzodiazepine use was seen.

\section{Changes in other drug use}

Data on non-benzodiazepine drug use among participants are presented in Table three. Considering the 35 participants who were followed up at both three and 12 months post-rescheduling, a majority of participants (60\%) had used cannabis in the previous 28 days at baseline, followed by alcohol (51\%), heroin (49\%), amphetamines (34\%), pharmaceutical opioids (20\%) and cocaine (14\%; table 3). One-third (31\%) of participants used anti-depressants, and 14\% anti-psychotics, mostly licit (prescribed) use. There were no 
significant changes in proportions used over the three waves. Days of use in the last 28 (calculated only for those participants who used each drug at each time point) are also reported for the three waves. No significant changes in frequency of use were seen.

\section{$<$ Insert Table three here $>$}

\section{Changes in mental and physical health}

Data on mental and physical health of participants are reported in Table four. At baseline, most (71\%) fell below the cutoff for normal cognition. Most (71\%) also fell below the Australian population norm for the physical (73\%) and mental (91\%) component scores of the SF36. Approximately half scored above the severe threshold for depression (54\%), anxiety (69\%), and stress (49\%). Insomnia was also clinically significant in $51 \%$ of participants. There were no significant changes in mental or physical health between baseline and follow up two, except for a decrease in the proportion with clinically significant insomnia.

Three, zero and two participants reported overdose due to benzodiazepine use in the last 3 months at baseline, follow up 1 and follow up 2 respectively. Being a relatively low frequency event, with the sample size the study was not powered to detect a difference on this measure.

\section{<insert table Four here>}

\section{Alprazolam availability and price}

At baseline, most of the sample reported using only illicit alprazolam $(n=45,79 \%)$, defined as any source that was not a participant's own prescription (e.g. supplier, other person's prescribed medication). Three participants (five percent) reported using prescribed alprazolam only, and nine (16\%) reported a combination of prescription and illicit sources. At 12 months follow-up, a similar proportion ( $n=20 / 28,80 \%)$ reported using only illicit alprazolam, six participants (21\%) reported prescribed use only, and two participants reported a combination of prescription and illicit sources. Seven participants (25\%) had not used alprazolam in the previous three months.

The most common form of illicit alprazolam was $2 \mathrm{mg}$ tablets - the strongest dose formulation available in Australia. The cost of 'street' alprazolam doubled, rising from a mode of $\$ 5$ (20 out of 35 participants who reported a street price) per $2 \mathrm{mg}$ tab at baseline to $\$ 10$ (reported by $4 / 12$ ) at three month follow up and $\$ 10$ 
(reported by 22/31) at 12 month follow-up. Too few people reported purchase of lower strength tablets to report meaningful estimates. 


\section{Conclusions}

Using a longitudinal study design with within subject analyses, we were able to examine the effect of a change in the scheduling of alprazolam in a population of OST clients who report regular benzodiazepine use. To the authors knowledge this is the first prospectively conducted cohort study examining the impact of benzodiazepine up-scheduling. We found that alprazolam use reduced significantly in this population at three months follow up which was maintained at 12 months follow up but not eliminated. Total benzodiazepine consumption also reduced at 12 months compared to baseline. Furthermore, there was no evidence of substitution with other drug classes, with patterns of cannabis, alcohol, opioid, stimulant and other psychiatric medications (antidepressants, antipsychotic medications) remaining stable.

Following the change in scheduling the street price for $2 \mathrm{mg}$ alprazolam (the most commonly used strength amongst this cohort) increased, consistent with a reduction in its availability. Monitoring of street prices in larger surveillance studies such as the Illicit Drug Reporting System (Stafford \& Burns, 2013) will further inform about the effect of this change on broader populations of people who use drugs.

Similarly, there were few observable changes in a range of self-reported health outcomes, suggesting that unintended harms (such as increased mental health or sleep problems) were not experienced by this group as a result of the scheduling change and associated reduction in total benzodiazepine use. Indeed, this study observed reductions in insomnia over time.

These findings are similar to a multicentre Australian cross-sectional study of the effects of a restriction in government subsidies for the capsule formulation of temazepam in 2002 (Breen, Degenhardt, Bruno, Roxburgh, \& Jenkinson, 2004). This study also identified that few unintended harms were observed and there was some reduction in capsule prescription and injection, though many did continue to source and use this medication. However, injecting harms did continue to be observed until the product was removed from the market in 2004 (Degenhardt et al., 2008). It will be important to examine the longer-term outcomes of this scheduling change of alprazolam to determine if the medium-term benefits (reduced total benzodiazepine use) are maintained. 
As alprazolam continues to be available, particularly from illicit sources for this cohort, it is unlikely that all of the concerns relating to alprazolam use will be addressed by this recent scheduling change. It is worth noting that a minority of participants continued to source alprazolam via prescription, despite the regulatory change restricting prescription to OST clients. We do not know if prescribing doctors were compliant with the regulations requiring them to seek authority prior to prescribing alprazolam to these participants, and there is limited capacity to monitor or enforce the regulatory changes. Nevertheless, reduced access appeared to follow the regulatory changes. Real-time prescription monitoring programs may provide another tool to enforce regulatory change, but given the majority of alprazolam use in this sample was illicit (not from people's own prescriptions) prescription monitoring may only have an indirect effect by reducing the volume of illicit alprazolam available.

Long-term effects on cognitive function have been well described with benzodiazepine use (Barker, Greenwood, Jackson, \& Crowe, 2004). It is possible that with some continuing benzodiazepine and other drug use (and relatively high doses of diazepam equivalents at each time point) that we were not able to detect the changes in cognitive and general function. How best to achieve abstinence or even stable reduced doses of benzodiazepines remains an important and challenging clinical area in which further work is sorely needed, particularly for an OST population (Lintzeris \& Nielsen, 2010). Given the high rates of benzodiazepine use among opioid dependent treatment populations internationally (Chen et al., 2011; Heikman, Sundström, Pelander, \& Ojanperä, 2016; Meiler et al., 2005; Park, Bohnert, Austin, Saitz, \& Pizer, 2014), cognitive effects of benzodiazepines remain an issue of significant public health concern

There are some important limitations in interpreting these data. Firstly, the small sample size may restrict power to detect both changes over time and predictors of change. Secondly, some recall bias amongst a cognitively impaired sample of OST clients who use benzodiazepines is possible, though with careful use of time-line follow back methods most participants were able to report their substance use in detail, and timeline follow back is a validated method of data collection amongst substance using populations (Hjorthøj, Hjorthøj, \& Nordentoft, 2012; Sacks, Drake, Williams, Banks, \& Herrell, 2003; Sobell \& Sobell, 1992). Although self-report was not supplemented with objective measures such as urine drug screens, the latter would also have been restricted to indicating recent use only without indicating frequency or volume of use. Despite the small sample, clear changes were able to be observed. While small, this sample represents one of the highest risk populations at which regulatory changes were targeted. Another potential limitation is the 
absence of a comparison group, and it is possible that some of the identified changes over time (such as reduced total benzodiazepine use) may represent maturation cohort effects of remaining in long term OST treatment - as suggested in previous OST studies (Brands et al., 2008). This study was restricted to OST clients only; results are not necessarily representative of drug using populations in general. The authors are aware of other cohorts (e.g. Illicit Drug Reporting System) monitoring changes among non-OST populations and look forward to the findings of these studies with interest. The last limitation is the follow-up rate of $61 \%$. Those lost to follow-up did not differ from those followed up on most variables, but they did have significantly longer benzodiazepine use histories. This raises concerns about whether patterns of drug use in followed up participants was representative of the whole sample.

Strengths of the study include a prospective cohort design with a statistical analysis taking account of missing data, detailed measures of substance use and well validated measures that may capture a range of unintended harms from restriction of alprazolam. The population recruited are broadly representative of OST patients in NSW more generally being on standard OST doses, mostly being male and prescribed methadone, and representing an ageing OST cohort has had been identified in other data collection sources (Australian Institute of Health and Welfare, 2014).

Twelve months after the scheduling change we were able to detect significant reductions in both alprazolam use, and total benzodiazepine use amongst this high-risk population without observing unintended harms in terms of measures of sleep, mental health or non-benzodiazepine substance use. Examining the effects amongst other at risk populations, and over longer time periods is important further work.

\section{Implications}

Regulatory changes in pharmaceutical medications can impact upon the accessibility and patterns of use of medications. This study indicates that the regulatory change of rescheduling alprazolam from S4 to S8 was associated with reduced levels of alprazolam and total benzodiazepine use in a high-risk population of OST clients.

\section{Conflict of interest}

None. 


\section{Acknowledgements}

Thank you to the study participants for their contributions, and to staff at the Langton Centre, St George and Rankin Court OSTs for facilitating recruitment. We also thank Associate Professor Timothy Dobbins for his assistance with statistical analyses. This study was funded by a grant from the Mental Health and Drug and Alcohol Office, NSW Health. 


\section{References}

Ashton, H. (2005). The diagnosis and management of benzodiazepine dependence. Curr Opin Psychiatry, 18(3), 249-255. doi: 10.1097/01.yco.0000165594.60434.84

Australian Institute of Health and Welfare. (2014). National opioid pharmacotherapy statistics 2013. Drug treatment series no. 23. Cat. no. HSE 147. Canberra: AIHW.

Barker, M. J., Greenwood, K. M., Jackson, M., \& Crowe, S. F. (2004). Cognitive effects of long-term benzodiazepine use: a meta-analysis. CNS Drugs, 18(1), 37-48.

Bastien, C. H., Vallieres, A., \& Morin, C. M. (2001). Validation of the Insomnia Severity Index as an outcome measure for insomnia research. Sleep Med, 2(4), 297-307.

Brands, B., Blake, J., Marsh, D. C., Sproule, B., Jeyapalan, R., \& Li, S. (2008). The Impact of Benzodiazepine Use on Methadone Maintenance Treatment Outcomes. Journal of Addictive Diseases, 27(3), 37-48. doi: 10.1080/10550880802122620

Breen, C. L., Degenhardt, L. J., Bruno, R. B., Roxburgh, A. D., \& Jenkinson, R. (2004). The effects of restricting publicly subsidised temazepam capsules on benzodiazepine use among injecting drug users in Australia. Med J Aust, 181(6), 300-304.

Buykx, P., Loxley, W., Dietze, P., \& Ritter, A. (2010). Medications used in overdose and how they are acquired - an investigation of cases attending an inner Melbourne emergency department. Australian and New Zealand Journal of Public Health, 34(4), 401-404. doi: 10.1111/j.1753-6405.2010.00573.x

Chen, K., Berger, C., Forde, D., D'Adamo, C., Weintraub, E., \& Gandhi, D. (2011). Benzodiazepine Use and Misuse Among Patients in a Methadone Program. BMC Psychiatry, 11(1), 90.

Darke, S., Hall, W., Ross, M., \& Wodak, A. (1992). Benzodiazepine use and HIV risk-taking behaviour among injecting drug users. Drug Alcohol Depend, 31(1), 31-36.

Darke, S., Ross, J., Mills, K., Teesson, M., Williamson, A., \& Havard, A. (2010). Benzodiazepine use among heroin users: Baseline use, current use and clinical outcome. Drug Alcohol Rev, 29(3), 250 - 255.

Deacon, R. M., Lintzeris, N., Leung, S., Malcolm, A., Finch, T., \& Holmes, J. (2014). Drug use trends among opioid treatment program clients in south-eastern Sydney. Drug Alcohol Rev, 33(S1), 23-24.

Degenhardt, L., Roxburgh, A., Van Beek, I., Hall, W. D., Robinson, M. K. F., Ross, J., \& Mant, A. (2008). The effects of the market withdrawal of temazepam gel capsules on benzodiazepine injecting in Sydney, Australia. Drug and Alcohol Review, 27(2), 145-151. doi: 10.1080/09595230701829413

Heikman, P., Sundström, M., Pelander, A., \& Ojanperä, I. (2016). New psychoactive substances as part of polydrug abuse within opioid maintenance treatment revealed by comprehensive high-resolution mass spectrometric urine drug screening. Human Psychopharmacology: Clinical and Experimental, 31(1), 44-52. doi: 10.1002/hup.2512

Hjorthøj, C. R., Hjorthøj, A. R., \& Nordentoft, M. (2012). Validity of Timeline Follow-Back for selfreported use of cannabis and other illicit substances - Systematic review and meta-analysis. Addictive Behaviors, 37(3), 225-233. doi: 10.1016/j.addbeh.2011.11.025

Horyniak, D., Reddel, S., Quinn, B., \& Dietze, P. (2012). The use of alprazolam by people who inject drugs in Melbourne, Australia. Drug Alcohol Rev, 31(4), 585-590. doi: 10.1111/j.14653362.2011.00381.x

Iguchi, M., Handelsman, L., Bickel, W., \& Griffiths, R. (1993). Benzodiazepine and sedative use/abuse by methadone maintenance clients. Drug Alcohol Depend, 32(3), 257 - 266.

IMS Institute for Healthcare Informatics. (2015). Medicines Use and Spending Shifts: A Review of the Use of Medicines in the U.S. in 2014: IMS Institute for Healthcare Informatics,. 
Isbister, G. K., O'Regan, L., Sibbritt, D., \& Whyte, I. M. (2004). Alprazolam is relatively more toxic than other benzodiazepines in overdose. British Journal of Clinical Pharmacology, 58(1), 8895. doi: 10.1111/j.1365-2125.2004.02089.x

Islam, M. M., Conigrave, K. M., Day, C. A., Nguyen, Y., \& Haber, P. S. (2014). Twenty-year trends in benzodiazepine dispensing in the Australian population. Internal Medicine Journal, 44(1), 57-64. doi: 10.1111/imj.12315

Jones, C. M., Lurie, P. G., \& Throckmorton, D. C. (2016). Effect of US drug enforcement administration's rescheduling of hydrocodone combination analgesic products on opioid analgesic prescribing. JAMA Internal Medicine. doi: 10.1001/jamainternmed.2015.7799

Jones, K., Nielsen, S., Bruno, R., Frei, M., \& Lubman, D. (2011). Benzodiazepine prescribing and violence: implications for general practitioners. Australian Family Physician, 40(11), 862865.

Kamal, F., Flavin, S., Campbell, F., Behan, C., Fagan, J., \& Smyth, R. (2007). Factors affecting the outcome of methadone maintenance treatment in opiate dependence. Ir Med J, 100(3), 393-397.

Lavie, E., Fatseas, M., Denis, C., \& Auriacombe, M. (2009). Benzodiazepine use among opiatedependent subjects in buprenorphine maintenance treatment: Correlates of use, abuse and dependence. Drug Alcohol Depend, 99(1-3), 338 - 344.

Lintzeris, N., \& Nielsen, S. (2010). Benzodiazepines, Methadone and Buprenorphine: Interactions and Clinical Management. 19(1), 59-72.

Lovibond, S. H., \& Lovibond, P. F. (1995). Manual for the Depression Anxiety Stress Scales. (2nd. Ed.) Psychology Foundation. Sydney.

Meiler, A., Mino, A., Chatton, A., \& Broers, B. (2005). Benzodiazepine use in a methadone maintenance programme: patient characteristics and the physician's dilemma. Schweizer Archiv für Neurologie und Psychiatrie, 156(6), 310-317.

Moylan, S., Giorlando, F., Nordfjaern, T., \& Berk, M. (2012). The role of alprazolam for the treatment of panic disorder in Australia. Australian and New Zealand Journal of Psychiatry, 46(3), 212-224. doi: 10.1177/0004867411432074

Moylan, S., Staples, J., Ward, S. A., Rogerson, J., Stein, D. J., \& Berk, M. (2011). The efficacy and safety of alprazolam versus other benzodiazepines in the treatment of panic disorder. $J$ Clin Psychopharmacol, 31(5), 647-652. doi: 10.1097/JCP.0b013e31822d0012

Nasreddine, Z. S., Phillips, N. A., Bedirian, V., Charbonneau, S., Whitehead, V., Collin, I., . . . Chertkow, H. (2005). The Montreal Cognitive Assessment, MoCA: a brief screening tool for mild cognitive impairment. J Am Geriatr Soc, 53(4), 695-699. doi: 10.1111/j.15325415.2005.53221.x

National Prescribing Service. (1999). National Prescribing Service Newsletter (pp. 5).

Nielsen, S., Bruno, R., Carruthers, S., Fischer, J., Lintzeris, N., \& Stoove, M. (2008). Investigation of pharmaceutical misuse amongst drug treatment clients Report commissioned by the Ministerial Council on Drug Strategy through the Cost Shared Funding Model with the Victorian Department of Human Services. Melbourne: Turning Point Alcohol and Drug Centre Inc.

Nielsen, S., Dietze, P., Lee, N., Dunlop, A., \& Taylor, D. (2007). Concurrent buprenorphine and benzodiazepines use and self-reported opioid toxicity in opioid substitution treatment. Addiction, 102(4), 616-622.

Park, T. W., Bohnert, A. S., Austin, K. L., Saitz, R., \& Pizer, S. D. (2014). Datapoints: Regional Variation in Benzodiazepine Prescribing for Patients on Opioid Agonist Therapy. Psychiatric Services, 65(1), 4-4. doi: 10.1176/appi.ps.201300419 
Park, T. W., Saitz, R., Ganoczy, D., Ilgen, M. A., \& Bohnert, A. S. B. (2015). Benzodiazepine prescribing patterns and deaths from drug overdose among US veterans receiving opioid analgesics: case-cohort study. BMJ, 350.

Peles, E., Schreiber, S., \& Adelson, M. (2010). 15-Year survival and retention of patients in a general hospital-affiliated methadone maintenance treatment (MMT) center in Israel. Drug Alcohol Depend, 107(2-3), 141 - 148.

Poisons and Therapeutic Goods Act 1966 [statute on the internet]. Retrieved 10 April 2015, from http://www.legislation.nsw.gov.au/viewtop/inforce/act+31+1966+FIRST+0+N/

Rintoul, A., Dobbin, M., Nielsen, S., Degenhardt, L., \& Drummer, O. (2013). Recent increase in detection of alprazolam in Victorian heroin-related deaths. Medical Journal of Australia, 198(4), 206-209.

Sacks, J. A. Y., Drake, R. E., Williams, V. F., Banks, S. M., \& Herrell, J. M. (2003). Utility of the timeline follow-back to assess substance use among homeless adults. Journal of Nervous and Mental Disease, 191(3), 145-153. doi: 10.1097/00005053-200303000-00002

Sobell, L. C., \& Sobell, M. B. (1992). Timeline Follow-back: a technique for assessing self-reported ethanol consumption. In L. R. T. Allen J (Ed.), In Measuring alcohol consumption: psychosocial and biological methods (pp. 41-72): Humana Press.

Stafford, J., \& Burns, L. (2013). Findings from the Illicit Drug Reporting System (IDRS) Australian Drug Trends 2013. Sydney.

Substance Abuse and Mental Health Services Administration. (2013). Drug Abuse Warning Network, 2011: National Estimates of Drug-Related Emergency Department Visits DAWN Series (Vol. D-39). Rockville, MD.

Therapeutic Guidelines Limited. (2013). eTG complete: Psychotropic Guidelines. Melbourne. 2013, from http://etg.tg.com.au/complete/

Truven Health Analytics. Micromedex. Greenwood Village, CO, USA.

Ware, J. E., Jr., \& Sherbourne, C. D. (1992). The MOS 36-item short-form health survey (SF-36). I. Conceptual framework and item selection. Med Care, 30(6), 473-483.

Wolf, B., \& Griffiths, R. R. (1991). Physical dependence on benzodiazepines: differences within the class. Drug Alcohol Depend, 29(2)(0376-8716 (Print)), 153-156. 
Table one. Participant demographics, physical and mental health at baseline, comparing those followed up and not followed up at 12 months

\begin{tabular}{|l|l|l|l|l|}
\hline & $\begin{array}{l}\text { A. Total } \\
\text { sample, } \mathbf{n = 5 7}\end{array}$ & $\begin{array}{l}\text { B. Followed up } \\
\text { at 12 months, } \\
\mathbf{n = 3 5}\end{array}$ & $\begin{array}{l}\text { C .12 months not } \\
\text { followed up, } \mathbf{n = 2 2}\end{array}$ & $\mathbf{p ~ ( B ~ v ~ C ) ~}$ \\
\hline Age, mean (SD) & $44(8.7)$ & $44(8.9)$ & $44(8.7)$ & $0.959^{1}$ \\
\hline Gender, $\mathbf{n}(\%)$ male & $34(60 \%)$ & $21(60 \%)$ & $13(59 \%)$ & $1.000^{2}$ \\
\hline Completed high school, $\mathbf{n}(\%)$ & $19(33 \%)$ & $15(43 \%)$ & $4(18 \%)$ & $0.083^{3}$ \\
\hline Employed at baseline, $\mathbf{n}(\%)$ & $4(7 \%)$ & $3(9 \%)$ & $1(4 \%)$ & $1.000^{3}$ \\
\hline Homeless at baseline, $\mathbf{n}(\%)$ & $5(9 \%)$ & $3(9 \%)$ & $2(9 \%)$ & $1.000^{3}$ \\
\hline $\begin{array}{l}\text { Opioid substitution medication } \\
\text { type methadone, } \mathbf{n}(\%)\end{array}$ & $47(82 \%)$ & $28(80 \%)$ & $19(86 \%)$ & $0.725^{2}$ \\
\hline $\begin{array}{l}\text { Years regular benzodiazepine } \\
\text { use, median (range) }\end{array}$ & $15.5(1-53)$ & $8.5(1-40)$ & $24.5(3-53)$ & $\begin{array}{l}\mathrm{U}=185, \\
\mathrm{p}=0.002^{4}\end{array}$ \\
\hline
\end{tabular}

${ }^{1}$ ANOVA

${ }^{2}$ chi-square test

${ }^{3}$ Fischer's exact test

${ }^{4}$ Mann-Whitney test 
Table two: Linear mixed model results for alprazolam and total benzodiazepine use over 3 time points.

\begin{tabular}{|c|c|c|c|c|c|}
\hline \multirow{2}{*}{$\begin{array}{l}\begin{array}{l}\text { Dependent } \\
\text { variable }\end{array} \\
\text { Model 1: Total } 7 \\
\text { day alprazolam } \\
\text { load mg }\end{array}$} & \multirow{2}{*}{$\begin{array}{l}\text { Model } \\
\text { Base }\end{array}$} & \multirow{2}{*}{$\begin{array}{l}\text { Independent variables } \\
\text { Timepoint }\end{array}$} & \multicolumn{2}{|c|}{ Estimations } & \multirow{2}{*}{$\begin{array}{l}\mathbf{p} \\
- \\
0.007 \\
0.001\end{array}$} \\
\hline & & & $\begin{array}{l}\text { Baseline } \\
3 \text { months } \\
12 \text { months }\end{array}$ & $\begin{array}{l}14.9(10.8-19.0) \\
8.3(3.9-12.6) \\
6.3(1.5-11.2)\end{array}$ & \\
\hline & Best fit & $\begin{array}{l}\text { Timepoint + SF-36 } \\
\text { physical component score } \\
+ \text { insomnia }^{2}+\text { stress }^{3}\end{array}$ & $\begin{array}{l}\text { Baseline } \\
3 \text { months } \\
12 \text { months }\end{array}$ & $\begin{array}{l}15.1(11.0-19.3) \\
8.7(4.3-13.1) \\
6.1(1.2-11.1)\end{array}$ & $\begin{array}{l}- \\
0.009 \\
0.001\end{array}$ \\
\hline \multirow[t]{2}{*}{$\begin{array}{l}\text { Model 2: } \\
\text { Alprazolam, days } \\
\text { of use in last } 28\end{array}$} & Base & Timepoint & $\begin{array}{l}\text { Baseline } \\
3 \text { months } \\
12 \text { months }\end{array}$ & $\begin{array}{l}14.1(11.3-16.8) \\
8.6(5.8-11.4) \\
7.9(4.8-11.1)\end{array}$ & $\begin{array}{l}- \\
<0.001 \\
0.001\end{array}$ \\
\hline & Best fit & $\begin{array}{l}\text { Timepoint + site + SF-36 } \\
\text { physical component score } \\
+ \text { insomnia }^{2}\end{array}$ & $\begin{array}{l}\text { Baseline } \\
3 \text { months } \\
12 \text { months }\end{array}$ & $\begin{array}{l}13.7(10.7-16.6) \\
8.5(5.5-11.4) \\
7.1(3.7-10.5)\end{array}$ & $\begin{array}{l}- \\
0.001 \\
0.001\end{array}$ \\
\hline \multirow{2}{*}{$\begin{array}{l}\text { Model 3: Total } 7 \\
\text { day all } \\
\text { benzodiazepine } \\
\text { load, diazepam } \\
\text { equivalent mg }\end{array}$} & Base & Timepoint & $\begin{array}{l}\text { Baseline } \\
3 \text { months } \\
12 \text { months }\end{array}$ & $\begin{array}{l}222(142-303) \\
212(126-298) \\
157(70-245)\end{array}$ & $\begin{array}{l}- \\
0.857 \\
0.044\end{array}$ \\
\hline & Best fit & $\begin{array}{l}\text { Timepoint }+ \text { SF-36 } \\
\text { physical component score } \\
+ \text { insomnia }^{2}+\text { anxiety }^{3}\end{array}$ & $\begin{array}{l}\text { Baseline } \\
3 \text { months } \\
12 \text { months }\end{array}$ & $\begin{array}{l}225(144-306) \\
223(136-310) \\
151(63-239)\end{array}$ & $\begin{array}{l}- \\
0.972 \\
0.028\end{array}$ \\
\hline \multirow{2}{*}{$\begin{array}{l}\text { Model 4: All } \\
\text { benzodiazepines, } \\
\text { days of use in } \\
\text { last } 28\end{array}$} & Base & Timepoint & $\begin{array}{l}\text { Baseline } \\
3 \text { months } \\
12 \text { months }\end{array}$ & $\begin{array}{l}18.8(15.9-21.8) \\
17.0(13.8-20.1) \\
14.9(11.4-18.5)\end{array}$ & $\begin{array}{l}- \\
0.274 \\
0.040\end{array}$ \\
\hline & Best fit & $\begin{array}{l}\text { Timepoint + SF-36 } \\
\text { physical component score } \\
+ \text { insomnia }^{2}\end{array}$ & $\begin{array}{l}\text { Baseline } \\
3 \text { months } \\
12 \text { months }\end{array}$ & $\begin{array}{l}18.5(15.5-21.4) \\
17.1(13.9-20.2) \\
14.7(11.1-18.3)\end{array}$ & $\begin{array}{l}- \\
0.434 \\
0.065\end{array}$ \\
\hline
\end{tabular}

\footnotetext{
${ }^{1}$ Measured using the SF-36v2 Health Survey

${ }^{2}$ Measured using the Insomnia Severity Index

${ }^{3}$ Measured using the short form version of the Depression Anxiety Stress Scales.
} 
Table three: Changes in proportion and frequency of non-benzodiazepine substance use among 35 participants followed up at timepoints 2 and 3 . Mean days of use is calculated using only those participants who used at each timepoint.

\begin{tabular}{|c|c|c|c|c|c|c|}
\hline & & \multirow{2}{*}{$\begin{array}{l}\text { Baseline } \\
(n=35)\end{array}$} & \multirow{2}{*}{$\begin{array}{l}\text { Follow up } 1 \\
(n=35)\end{array}$} & \multirow{2}{*}{$\begin{array}{l}\text { Follow up } 2 \\
(n=35)\end{array}$} & \multicolumn{2}{|c|}{ p (McNemar) } \\
\hline & & & & & $\begin{array}{l}\text { Baseline vs } \\
\text { Follow up } 2\end{array}$ & $\begin{array}{l}\text { Follow up } 1 \text { vs } \\
\text { Follow up } 2\end{array}$ \\
\hline \multirow[t]{2}{*}{ Heroin } & \% used & $17(49)$ & $14(41)$ & $14(40)$ & 0.375 & 1.000 \\
\hline & $\begin{array}{l}\text { Mean days of use } \\
\text { (SD) }\end{array}$ & $9(8)$ & $9(7)$ & 9 (8) & - & \\
\hline \multirow{2}{*}{$\begin{array}{l}\text { Pharmaceutical } \\
\text { opioids }\end{array}$} & $\%$ used & $7(20)$ & $3(9)$ & $4(11)$ & 0.375 & 1.000 \\
\hline & $\begin{array}{l}\text { Mean days of use } \\
\text { (SD) }\end{array}$ & $8(10)$ & 2 (2) & $7(9)$ & - & \\
\hline \multirow[t]{2}{*}{ Amphetamines } & \% used & $12(34)$ & $11(32)$ & $11(32)$ & 1.000 & 1.000 \\
\hline & $\begin{array}{l}\text { Mean days of use } \\
\text { (SD) }\end{array}$ & $6(6)$ & $6(6)$ & $4(6)$ & - & \\
\hline \multirow[t]{2}{*}{ Cocaine } & $\%$ used & $5(14)$ & $4(12)$ & $0(0)$ & 0.063 & 0.125 \\
\hline & $\begin{array}{l}\text { Mean days of use } \\
\text { (SD) }\end{array}$ & $4(2)$ & $4(6)$ & $4(4)$ & - & \\
\hline \multirow[t]{2}{*}{ Cannabis } & $\%$ used & $21(60)$ & $18(53)$ & $21(60)$ & 1.000 & 0.625 \\
\hline & $\begin{array}{l}\text { Mean days of use } \\
\text { (SD) }\end{array}$ & $17(12)$ & $17(11)$ & $19(11)$ & - & \\
\hline \multirow[t]{2}{*}{ Alcohol } & \% used & $18(51)$ & $16(48)$ & $18(51)$ & 1.000 & 1.000 \\
\hline & $\begin{array}{l}\text { Mean days of use } \\
\text { (SD) }\end{array}$ & $13(10)$ & $12(10)$ & $10(10)$ & - & \\
\hline \multirow[t]{2}{*}{ Antidepressants } & $\%$ used & $11(31)$ & $11(32)$ & $11(31)$ & 1.000 & 1.000 \\
\hline & $\begin{array}{l}\text { Mean days of use } \\
\text { (SD) }\end{array}$ & $20(12)$ & $19(12)$ & $25(8)$ & - & \\
\hline \multirow[t]{2}{*}{ Antipsychotics } & $\%$ used & $5(14)$ & $6(18)$ & $7(21)$ & 0.687 & 1.000 \\
\hline & $\begin{array}{l}\text { Mean days of use } \\
\text { (SD) }\end{array}$ & $24(7)$ & $23(7)$ & $21(13)$ & - & \\
\hline
\end{tabular}


Table four: Changes in mean scores and proportion scoring below normal range of physical and mental health markers among 35 participants followed up at waves 2 and 3.

\begin{tabular}{|c|c|c|c|c|c|}
\hline & & $\begin{array}{l}\text { Baseline } \\
(n=35)\end{array}$ & $\begin{array}{l}\text { Follow up } 1 \\
(n=35)\end{array}$ & $\begin{array}{l}\text { Follow up } 2 \\
(n=35)\end{array}$ & $\begin{array}{l}\mathbf{p} \\
\text { (repeated } \\
\text { measures } \\
\text { ANOVA) }\end{array}$ \\
\hline \multirow{2}{*}{$\begin{array}{l}\text { Cognitive } \\
\text { impairment } \\
\text { score }^{1}\end{array}$} & Mean (SD) & $23.7(3.3)$ & $22.7(3.5)$ & $23.8(3.6)$ & 0.117 \\
\hline & $\begin{array}{l}\text { Proportion below } \\
\text { cutoff for normal } \\
\text { cognition }(<26)\end{array}$ & $71 \%$ & $79 \%$ & $60 \%$ & \\
\hline \multirow{2}{*}{$\begin{array}{l}\text { Physical } \\
\text { component } \\
\text { score }^{2}\end{array}$} & Mean (SD) & $45.6(9.5)$ & $48.3(10.1)$ & $46.1(10.5)$ & 0.234 \\
\hline & $\begin{array}{l}\text { Proportion below } \\
\text { population mean } \\
(<50.0)\end{array}$ & $69 \%$ & $56 \%$ & $60 \%$ & \\
\hline \multirow{2}{*}{$\begin{array}{l}\text { Mental } \\
\text { component } \\
\text { score }^{2}\end{array}$} & Mean (SD) & $32.0(9.4)$ & 34.2 (11.3) & 34.6 (13.4) & 0.434 \\
\hline & $\begin{array}{l}\text { Proportion below } \\
\text { population mean } \\
(<50.0)\end{array}$ & $91 \%$ & $91 \%$ & $83 \%$ & \\
\hline \multirow{2}{*}{$\begin{array}{l}\text { Depression } \\
\text { score }^{3}\end{array}$} & Mean (SD) & $11.6(5.9)$ & $10.3(6.1)$ & $9.7(6.2)$ & 0.291 \\
\hline & $\begin{array}{l}\text { Proportion above } \\
\text { severe cutoff }(\geq 11)\end{array}$ & $54 \%$ & $52 \%$ & $51 \%$ & \\
\hline \multirow[t]{2}{*}{ Anxiety score $^{3}$} & Mean (SD) & $8.9(4.0)$ & $8.7(4.3)$ & $7.3(5.0)$ & 0.200 \\
\hline & $\begin{array}{l}\text { Proportion above } \\
\text { severe cutoff }(\geq 8)\end{array}$ & $69 \%$ & $67 \%$ & $43 \%$ & \\
\hline \multirow[t]{2}{*}{ Stress score $^{3}$} & Mean (SD) & $11.5(4.6)$ & $12.3(4.8)$ & $10.1(5.0)$ & 0.108 \\
\hline & $\begin{array}{l}\text { Proportion above } \\
\text { severe cutoff }(\geq 13)\end{array}$ & $49 \%$ & $51 \%$ & $37 \%$ & \\
\hline \multirow{2}{*}{$\begin{array}{l}\text { Insomnia } \\
\text { score }^{4}\end{array}$} & Mean (SD) & $14.9(7.6)$ & $15.3(6.9)$ & $11.8(7.5)$ & $<0.001$ \\
\hline & $\begin{array}{l}\text { Proportion above } \\
\text { clinically significant } \\
\text { cutoff }(\geq 15)\end{array}$ & $51 \%$ & $68 \%$ & $37 \%$ & \\
\hline
\end{tabular}

${ }^{1}$ Measured using the Montreal Cognitive Assessment; scores above 25/30 indicate normal cognition

${ }^{2}$ Measured using the SF-36v2 Health Survey; US population norms are 50.

${ }^{3}$ Measured using the short form version of the Depression Anxiety Stress Scales; Cut-off scores out of 21 for severe or very severe depression, anxiety and/or stress are $11+, 8+$ and 13+ respectively.

${ }^{4}$ Measured using the Insomnia Severity Index; a score of 15 or above indicates clinically significant insomnia. 